\section{Sexual identity management of working lesbian women}

\author{
Kristine Khachatryan, Regine Graml, Tobias Hagen, Yvonne Ziegler \\ and Ricky Astrida Herman \\ Faculty of Business and Law, Frankfurt University of Applied Sciences, \\ Frankfurt am Main, Germany
}

\begin{abstract}
Purpose - The purpose of this study is to provide a closer look at being out in the work environment. What are the characteristics that distinguish lesbian women who are out at work from those who are not? What role do companies play with their diversity-related measures?

Design/methodology/approach - This paper investigates characteristics that distinguish lesbian women who were out at work and analyzes the use of various sexual identity management strategies in relation to specific reference groups within a company. Furthermore, the method of multiple correspondence analysis is used to visually map the associations between company-specific characteristics and being out.

Findings - Results show that being out in the work environment is subject to a complex interplay of several factors, from personal resources to the diversity-friendliness of the company. A company's lesbian, gay, bisexual, transgender, and intersexual (LGBTI)-related measures, such as in-house LGBTI networks or diversity workshops, can not only promote the coming out of lesbian employees, and thereby help to increase their overall satisfaction with life, but can also reduce their experiences of discrimination.

Originality/value - In this paper, the method of multiple correspondence analysis is used to examine the relationships between several diversity-related measures of the company and being out at the workplace. A visualization of these relationships in a two-dimensional space allows a more comprehensive view of these features and their possible effect on being out at the workplace.
\end{abstract}

Keywords Multiple correspondence analysis, Being out, Diversity sensitivity, Lesbian employee, Sexual identity management.

Paper type Research paper

\section{Introduction}

Research into the lesbian, gay, bisexual, transgender, and intersexual (LGBTI) movement has constantly changed over time. In the context of the work environment, three research waves can be recognized (Colgan and Rumens, 2015). The first wave begins at the end of the 1970s and focuses on experiences of discrimination. During the second wave, in the 1990s, research is carried out on a broader range of topics and aspects regarding homosexual workers, e.g. how they deal with their own sexual identity at work and how it influences career decisions. The third wave starts in the 21st century and focuses on the consequences of the improved legal situation for LGBTI people in the workplace, e.g. the emergence of

(C) Kristine Khachatryan, Regine Graml, Tobias Hagen, Yvonne Ziegler and Ricky Astrida Herman. Published in Organization Management Journal. Published by Emerald Publishing Limited. This article is published under the Creative Commons Attribution (CC BY 4.0) licence. Anyone may reproduce, distribute, translate and create derivative works of this article (for both commercial and non-commercial purposes), subject to full attribution to the original publication and authors. The full terms of this licence maybe seen at http://creativecommons.org/licences/by/4.0/legalcode
Sexual identity management

Received 9 January 2021 Revised 14 July 2021 26 November 2021 Accepted 25 January 2022 
OMJ 19,3

"gay-friendly" organizations. Scientists also begin to focus on the diversity of the LGBTI community and to consider the experiences of bisexual and transgender employees.

In Germany, the General Equal Treatment Act (AGG) came into force in 2006, prohibiting, among other things, sexual identity discrimination by private actors, e.g. employers and landlords (Antidiskriminierungsstelle des Bundes, 2020). In recent years, the number of employees who are out at work has increased in Germany. As surveys show, in $2007,51.9 \%$ of the lesbian and gay respondents said they spoke to (almost) none of their colleagues about their sexual identity (Frohn, 2007). Ten years later, that proportion had sunk to 30.6\% (Frohn et al., 2017). Another study indicates that, in 2019, a third of lesbian, gay, bisexual, transgender, queer und intersexual (LGBTQI*) [1] people had either not come out to their colleagues or were not explicitly open about their sexual orientation or gender identity (de Vries et al., 2020).

How comfortable an lesbian, gay, bisexual and transgender (LGBT+) employee feels at work depends on whether their sexual identity can be disclosed in that environment. On the one hand, having to hide their sexual orientation and not being able to show their true self at work (Steffens et al., 2016) causes them stress (Lehtonen, 2016). Coming out can then be an opportunity for personal development, better self-confidence, stable mental health, and a more honest and authentic relationship with their work colleagues (Rodriguez and Etengoff, 2016). On the other hand, being out at work poses a danger, because the process can convert the status of an employee from "discreditable" to "discredited" (Goffman, 2003).

Many studies examine LGBT+ people as one homogenous group, despite the heterogeneity within this group. However, the consideration of other identities within the LGBT+ community is important. For example, unlike heterosexual women and gay men, lesbian workers have to deal with sexism and heterosexism in the workplace to be successful in their careers (Gedro, 2006). As a research object, lesbian women are still underrepresented and should therefore be studied (Chung, 2003; Ng and Rumens, 2017; Gedro, 2019). This lack of research on lesbian women can also be observed for Germany (Losert, 2004).

This paper takes a closer look at what it means for lesbian women to be out at work. We will investigate characteristics that distinguish out lesbian working women. In addition, we will discuss various identity management strategies and analyze their use in relation to specific reference groups within a company. Furthermore, we will use the method of multiple correspondence analysis to analyze the role that companies play with their diversity-related measures. These questions will be answered on the basis of a 2019 online survey, which included responses from 713 lesbian women.

\section{Theoretical framework}

Unlike other minority groups, lesbian, gay and bisexual (LGB) people can choose to hide or disclose their stigmatized identity in the workplace (Gates and Viggiani, 2014). Because of the invisibility of their stigma, it is a challenge for them to decide whether or not to disclose their sexual identity at work (Ragins, 2004; Meinhold and Frohn, 2016; Ozeren and Aslan, 2016).

According to Frohn et al. (2017), lesbian and gay employees are less open about their sexual identity with their managers than with their colleagues. If a person is in a steady relationship or is a manager, they are more inclined to be open about their own sexual identity.

A study by Heintz (2012) found that lesbian managers benefited from coming out, because they were subsequently perceived as better suited to the male leadership league. Nonetheless, the majority of study participants were concerned about the effects of coming 
out on their career development, the reaction of board members and work colleagues, and their relationship with customers.

According to Trau (2015), an LGB-friendly working environment facilitates the comingout process and the establishment of LGB networks. Webster et al. (2017) found a connection between an LGB-friendly working environment and the willingness to come out. With an LGB-friendly policy, LGB employees can identify with the values of the organization and therefore have higher job satisfaction, which ultimately leads to a lower fluctuation rate (Day and Schoenrade, 1997; Velez and Moradi, 2012; Allan et al., 2015).

There are four strategies for the management of sexual identity. The first strategy, "Passing," is often considered the safest in terms of protection against discrimination. LGB employees who use this strategy convey the impression that they are heterosexual. The second strategy, "Covering," involves holding back any information that can lead to being outed, without pretending to be heterosexual. In the third strategy, "Implicitly Out," an LGB person does not explicitly call themselves LGB but does give indirect indications in this regard. Users of the fourth strategy, "Explicitly Out," identify themselves to others by openly communicating that they are homo- or bisexual (Griffin, 1992).

According to King et al. (2017), the use of revealing strategies (implicitly and explicitly out) is more likely to occur when interacting with other LGB people and with people who indicate acceptance of LGB people.

Köllen (2015) studied demographic factors for the application of identity management strategies at work. As in the study by Frohn et al. (2017), the relationship status of the employee was found to be an important factor, because employees who are in a permanent relationship tend to be "Explicitly Out." Furthermore, this strategy is used more frequently by older employees, by lesbian employees (compared to gay employees), by religious employees and by employees without a migration background. In a qualitative study by Lehtonen (2016), indications could be obtained that young people who are in a relationship also tend to be out. Presumably, this finding has more to do with the effect of being in a relationship than the effect of age. Furthermore, employees are more likely to be open about their sexual identity at larger companies, but also in smaller organizations of 10-50 employees and if they are part of an internal network or external professional association for LGBTI people (Frohn et al., 2017).

According to Hodson et al. (2018), a person's decision to come out is largely a function of several factors that can be classified within three sectors of an ecological model (Cukier et al., 2013): individual (micro); organizational and sectoral (meso); and societal (macro). At the center of the ecological model are the individual, and thus the individual characteristics (e.g. educational level, social and family background), that can influence a person's potential to succeed at work. Strong individual relationships can encourage LGBTQ+ people to be out with certain circles in their work environment (for a review of the LGBTQ+ work-family interface, see Murphy et al., 2021).

The organizational level is about the work culture and organizational guidelines, starting with the corporate rules on combating harassment at work. Organizational policy plays a crucial role in work culture as guidelines aimed at inclusion and antidiscrimination can influence the supportive attitude of colleagues and therefore have a direct impact on outness at work.

Some organizational guidelines were introduced to comply with existing antidiscriminatory policies such as the AGG in Germany. In recent years, scholars and companies have expanded their diversity practices to become inclusion practices. While diversity concentrates mainly on the diverse composition of a group, inclusion deals more with the involvement of these diverse members (Roberson, 2006). Shore et al. (2011) developed an inclusion framework and characterized inclusion as high belongingness to a group and high value of uniqueness. Hence, an inclusive organization encourages its 
OMJ 19,3

members to retain their unique characteristics (on the problem of organizational control of inclusion of gender/sexual subjects in the workplace, see Burchiellaro, 2020).

The sectoral level deals with barriers, interventions and strategies that exist between and within sectors, and then affects the perceived ability to come out in the workplace. Sectoral actors such as professional associations and regulatory agencies can greatly affect organizational inclusion. The culture regarding diversity and inclusion strongly differs from sector to sector. Sector-level organizations can create LGBTQ+ support policies, support networks or affinity groups, which can greatly influence the culture supporting sexual minorities. In the study by Frohn et al. (2017), most of those surveyed from sectors concerned with mining or extracting raw materials, electrical or automotive engineering, agriculture, forestry and fishery were not out, while those working in architecture, journalism and social professions tended to be out.

The last level in the model is the societal/macro level, which scrutinizes the broader cultural, social and governmental-ideological elements of society. The components at this level include legal protection, cultural admissibility for same-sex marriages and the representation of LGBTQ+ persons in the media.

\section{Data collection and methodology}

The data were collected in 2019 through an online survey. The obtained sample includes 713 lesbian women.

The authors are aware that the results cannot simply be extrapolated to the underlying population, as the sample in the online survey was self-selective. However, because of the size of the sample, it should be possible to examine being out at work to identify important factors associated with it.

First, we will give a description of the characteristics of out and non-out working women and examine the use of different identity management strategies. Then, with the help of a multiple correspondence analysis, the relationship between the company's characteristics and being out will be analyzed.

The procedure of the multiple correspondence analysis is very well suited to graphically depict relationships between several categorical variables. The possibility of mapping the similarities between categories as distances in a common space is an important reason why this method is often used (Blasius, 2010).

\section{Results: coming out in the workplace}

Who comes out in the workplace: essential differences

The distribution of the identity management strategies mainly used in the workplace shows that the Explicitly Out and Implicitly Out strategies prevailed among the lesbian women surveyed. Counting the Explicitly Out (46\%) and Implicitly Out (40\%) strategies together as Out, and the Covering (7\%) and Passing (1\%) strategies as Not Out, our data show that the group of out lesbian women outweighs the group of non-outs by about ten times. ${ }^{2}$

Table 1 provides an overview of the characteristics of out and non-out lesbian women. The table clearly shows that the out women mostly had partners. Another relevant difference between the two groups is their age: On average, the women who came out were older. We also found that the out lesbian women changed jobs more often than non-outs.

In addition, we discovered the following differences between the two groups, which, however, are not statistically significant: In terms of professional biography, our data show that the out lesbian women were more likely than the non-outs to hold a leadership position and generally had a longer history of professional experience. The number of women with university degrees was also higher among the group of out lesbian women. 


\begin{tabular}{|c|c|c|c|}
\hline & $\begin{array}{c}\text { Out } \\
(n=557)(\%)\end{array}$ & Not out $(n=50)(\%)$ & $\begin{array}{l}\text { Sexual identity } \\
\text { management }\end{array}$ \\
\hline $\begin{array}{l}\text { With a partner } \\
\text { Age* (average) } \\
\text { Up to } 25 \text { years old } \\
26-35 \text { years old } \\
36-45 \text { years old } \\
46-59 \text { years old } \\
\text { Over } 60 \text { years old }\end{array}$ & $\begin{array}{l}77 \\
41.3 \\
3 \\
28 \\
36 \\
30 \\
3\end{array}$ & $\begin{array}{l}56 \\
38.1 \\
4 \\
37 \\
39 \\
17 \\
2\end{array}$ & 103 \\
\hline $\begin{array}{l}\text { Highest level of education } \\
\text { Secondary school leaving certificate } \\
\text { Middle school } \\
\text { Abitur } \\
\text { Bachelor } \\
\text { Master/Diploma/Magister } \\
\text { PhD }\end{array}$ & $\begin{array}{r}2 \\
13 \\
17 \\
11 \\
47 \\
9\end{array}$ & $\begin{array}{r}0 \\
10 \\
28 \\
12 \\
38 \\
12\end{array}$ & \\
\hline $\begin{array}{l}\text { Leadership position } \\
\text { Professional experience (average) } \\
\text { Number of job changes* (average) }\end{array}$ & $\begin{array}{l}47 \\
15.1 \\
2.4\end{array}$ & $\begin{array}{l}40 \\
13.7 \\
1.7\end{array}$ & \\
\hline $\begin{array}{l}\text { Big Five personality traits (average) } \\
\text { Conscientiousness } \\
\text { Neuroticism } \\
\text { Openness* } \\
\text { Extraversion* } \\
\text { Agreeableness }\end{array}$ & $\begin{array}{l}3.9 \\
2.7 \\
3.7 \\
3.3 \\
3.2\end{array}$ & $\begin{array}{l}3.9 \\
2.9 \\
3.3 \\
2.9 \\
3.2\end{array}$ & $\begin{array}{r}\text { Table } 1 . \\
\text { Comparison of the } \\
\text { socio-demographic, }\end{array}$ \\
\hline $\begin{array}{l}\text { Overall life satisfaction" } \\
\text { Note: "Differences statistically signif }\end{array}$ & $\begin{array}{c}7.7 \\
\text { tney-U test or } \mathrm{I}\end{array}$ & 6.6 & $\begin{array}{r}\text { professional and } \\
\text { personal } \\
\text { characteristics }\end{array}$ \\
\hline
\end{tabular}

The examination of the Big Five personality dimensions reveals further differences between the two groups: out lesbian women were more open and extraverted and happier with their life.

Other differences between the outs and non-outs can be seen from their industry affiliation. The number of openly lesbian women in the workplace was higher in the field of information and communication. The group of outs also made up a larger share in areas such as trade and hospitality, and in economic services.

The group of non-outs were somewhat overrepresented, especially in the financial and insurance sector, but also in agriculture, forestry and fishery.

\section{Which group of coworkers were the women more out with?}

For the study, the different coming-out strategies were queried in relation to the following circles in the work environment: colleagues from the same department, colleagues from other departments, employees, direct superiors and managers from other departments.

The vast majority of lesbian respondents were explicitly or implicitly out to all reference groups. The strategies of passing and covering were therefore rarely used, but if they were, they were used comparatively more often with managers from other departments.

Colleagues from the same department were the reference group to which the respondents were the most likely to come out. These would be the people with whom the lesbian women 
OMJ 19,3

would have the most contact and who could therefore be regarded as their closest working environment. Our data show that if a lesbian woman was not out to colleagues from the same department, she was certainly not out to colleagues from other departments. These women also rarely came out to their direct superiors. However, lesbian women who indicated their sexual identity to colleagues from the same department also did so to other reference groups. Managers from other departments were the reference group to which the lesbian employees were the least likely to come out.

Out data show that $80 \%$ of the lesbian respondents were completely out in their work environment (i.e. across all reference groups). In contrast, $6 \%$ had not come out to any of the reference groups.

\section{Coming out and diversity sensitivity of a company}

Aside from the lesbian employees' own characteristics, company-specific features especially diversity management - play an important role in coming out in the workplace. To assess the extent to which diversity sensitivity within a company is related to coming out in the workplace, we mapped company-specific characteristics in a two-dimensional space with the variables being out and discrimination at current employer.

Figure 1 shows the result of the multiple correspondence analysis. The smaller the distance between two (or more) categories, the higher their similarities. For example, a small distance between the categories "V8_yes" and "V7_yes" means that external LGBTI events were more likely to be supported (V8) at companies where LGBTI was part of diversity management (V7). Proximity to the origin means that the corresponding category was selected by the majority of the respondents (e.g. "out": the majority of the lesbian women surveyed were out in the work environment).

The axes can be treated as latent variables, and the variable categories can be interpreted in relation to the axes. When a category is located close to a given axis, this means that the category is strongly determined by it (Thiessen and Blasius, 1998).

The horizontal axis can be interpreted as the diversity sensitivity of a company: On the positive side are the companies in which minority sensitivity and appropriate targeted measures are part of the corporate strategy. Accordingly, companies that do not implement such measures are located on the negative side. The category "2,000 and more employees" is located on the positive side of this dimension, which means that diversity sensitivity and measures are more characteristic of large companies. The categories for small- and mediumsized companies are located on the negative side, which means that comparatively fewer diversity-related measures are carried out in medium-sized and smaller companies. Interestingly, small companies with up to five employees are an exception. One explanation could be that in small companies such measures can be initiated and carried out more easily by the lesbian employees themselves due to the less formal corporate structure.

The figure shows that external LGBTI events are more likely to be financed by a company if LGBTI is part of its diversity management approach. An LGBTI employee network is more typical of companies where diversity workshops are held with and for employees. LGBTI executives are more likely to be found at large companies.

The meaning of the second, vertical dimension is less easy to interpret. On the positive side, this dimension can be described by the companies whose employees are not informed about the diversity sensitivity of the company. Small companies are placed in the negative range.

The "not out" category is in the positive area of the second dimension and in the negative area of the first dimension. This means that non-out women are often not informed about 


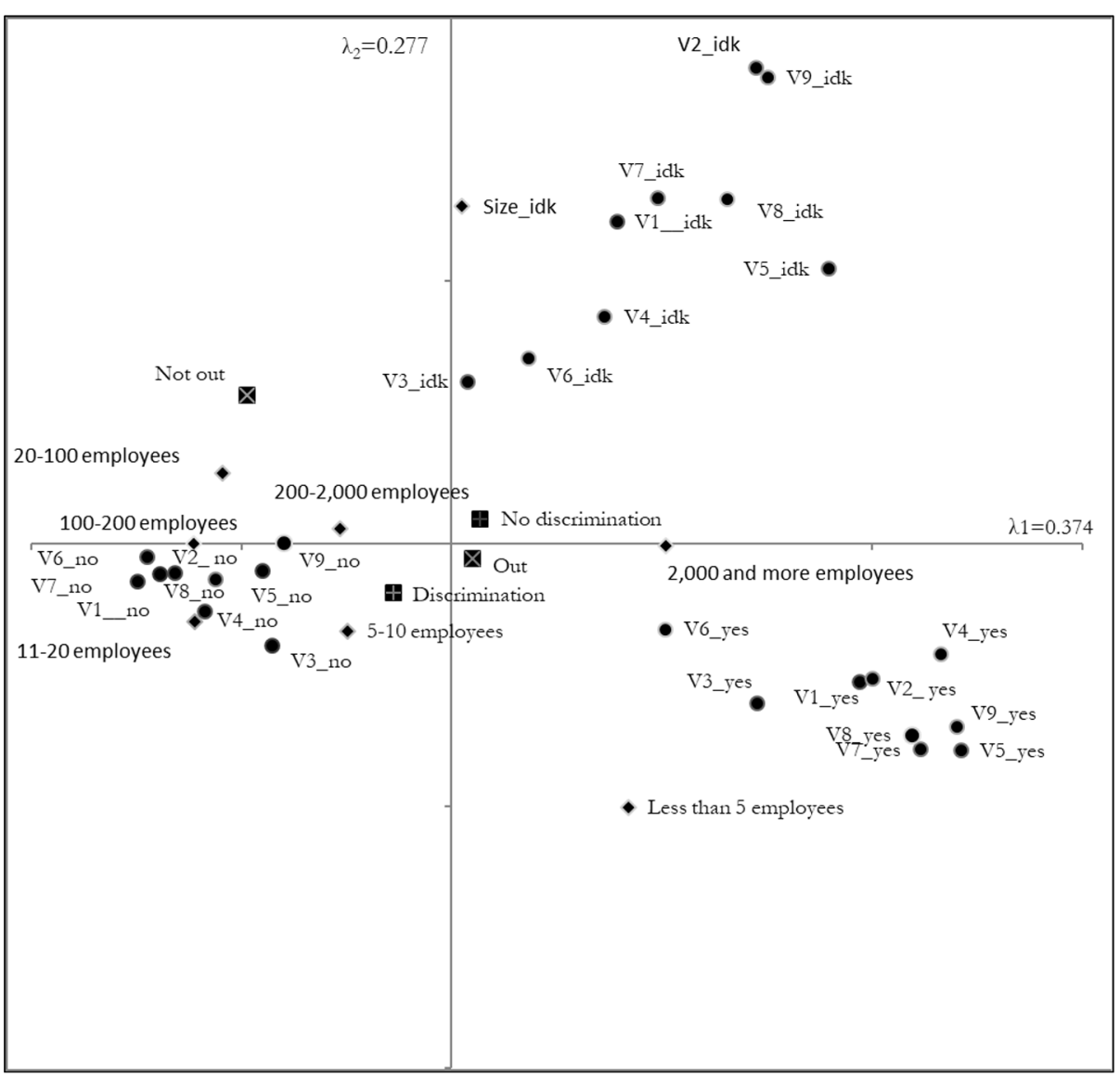

Notes: V1: Diversity management is a management task at the company; V2: There are one or more diversity managers at the company; V3: Diversity measures are accepted by all employees at the company; V4: Awareness-raising measures for managers are carried out at the company; V5: Diversity workshops are held with employees at the company; V6: There is at least one LGBTI manager; V7: LGBTI is part of diversity management at the company; V8: External LGBTI events are supported by the company, e.g. sponsoring events; V9: There is an LGBTI employee network within the company; _yes: property available; _no: property not available, _idk.: do not know

LGBTI measures at their company or work at a company in which such measures are not carried out.

The category "discrimination" is located in the negative area of the dimension "diversity sensitivity," which indicates that discrimination is more likely to be experienced at companies in which no diversity-related measures are carried out.
Sexual identity management

105

Figure 1. Company-specific characteristics, discrimination and coming out in the workplace: result of a multiple correspondence analysis 
OMJ

19,3

\section{Discussion}

In this paper, we investigated the characteristics that distinguish lesbian women in the workplace, and the role companies play with their diversity-related measures.

An important result of our study is that lesbian women who are not out have a significantly lower level of life satisfaction than comparable lesbian women who are out. A causal interpretation of this circumstance would be: Coming out increases life satisfaction. The causality could also be the opposite: People who are more satisfied with life are more likely to come out. Regarding these issues, we see need for further research.

With regard to individual factors that influence coming out, our results coincide with those of other studies. Partnership and age have significant influence on coming out.

Also, the personality characteristics "extraversion" and "openness" act as encouraging factors for being out. An interesting topic for future research would be the question of which factors encourage the coming out of introverted persons and to what extent their needs may differ.

Consistently with Trau (2015) and Webster et al. (2017), our results indicate that a lack of diversity measures at a company is often associated with lesbian employees concealing their sexual identity. One very alarming finding is that discrimination is more likely to be experienced in companies where no diversity measures are implemented.

Our results show that diversity measures are carried out more frequently in larger companies, which is also likely to be due to the cost aspect of these measures.

Diversity and inclusion measures such as awareness-raising workshops for managers and employees and employing diversity managers contribute to the well-being of employees, which can be seen in the higher life satisfaction of out women and is at the very least evident in their work performance (Oswald et al., 2015). Especially, small- and mediumsized companies must increase their efforts on diversity-related measures to keep up with larger companies in the war for talent. As can be seen from the Randstad Workmonitor 2020, German employees consider employee training, building a diverse workforce and hiring managers with diverse backgrounds to be the Top 3 most important factors when it comes to companies being more inclusive (Randstad, 2020). Also, companies should evaluate their communication strategy and strengthen the visibility of their LGBTI measures: Our data shows that if LGBTI networks are available within the company, this increases the likelihood of an explicit-out strategy by 19\% (analysis by Graml et al., 2020).

However, one significant limitation of this study is that the sample is not representative, and the survey participants were reached via different women's and LGBT networks. Therefore, the survey may not have reached - and thus included - lesbian women who are not part of such networks. The challenge for future research is that it is hard to obtain information on what a representative sample would look like as there is a lack of information on, and access to, non-out women.

In summary, the results show that being out at work, which is an important criterion for the general life satisfaction of a lesbian woman, is by no means an easy situational decision. Rather, it is subject to a complex interplay of several factors, from personal resources to the diversity-friendliness of the company, which manifests in the latter's diversity management approach and work culture and is industry-specific.

\section{Notes}

1. Please note: While this paper focuses on the sexual identity management of lesbian women in the workplace, we have cited various studies on gender and sexual diversity. This explains the use of different terms ranging from LGB to LGBQTI+. The plus sign or asterisk represent other identities.

2. The corresponding tables and figures are available on request. 


\section{References}

Sexual identity

Allan, B. A., Tebbe, E. A., Duffy, R. D., \& Autin, K. L. (2015). "Living a calling, life satisfaction, and workplace climate among a lesbian, gay, and bisexual population”. The Career Development Quarterly, 63(4), 306-319, doi: 10.1002/cdq.12030.

Antidiskriminierungsstelle des Bundes, (2020). "Allgemeines gleichbehandlungsgesetz (AGG) (13. ed.)".

Blasius, J. (2010). "Korrespondenzanalyse". in Wolf, C. and Best H., (Eds), Handbuch der sozialwissenschaftlichen datenanalyse, Wiesbaden: VS.

Burchiellaro, O. (2020). "Queering control and inclusion in the contemporary organization: on 'LGBT-friendly control' and the reproduction of (queer) value”. Organization Studies, 0170840620944557.

Chung, Y.B. (2003). "Career counseling with lesbian, gay, bisexual, and transgendered persons: the next decade". The Career Development Quarterly, 52(1), 78-86, doi: 10.1002/j.21610045.2003.tb00630.x.

Colgan, F. \& Rumens, N. (2015). "Understanding sexual orientation at work". In F. Colgan \& N. Rumens, (Eds), Sexual orientation at work: Contemporary issues and perspectives, pp. 1-27. Routledge.

Cukier, W., Gagnon, S., Mae Lindo, L., Hannan, C., and Amato, S. (2013). "A [critical] ecological model to enabling change: Promoting diversity and inclusion".iIn In Murphy, J., Malin, V. \& Siltaoja, M. (Eds), Getting things done (dialogues in critical management studies, Vol. 2, pp. 245-275. Emerald.

Day, N.E. \& Schoenrade, P. (1997). "Staying in the closet versus coming out: Relationships between communication about sexual orientation and work attitudes". Personnel Psychology, 50(1), 147-163, doi: 10.1111/j.1744-6570.1997.tb00904.x.

Frohn, D. (2007). "Out im office?!". Sexuelle Identität, (Anti-)Diskriminierung und Diversity am Arbeitsplatz. Edited by S. Netzwerk. Köln,

Frohn, D., Meinhold, F. \& Schmidt, C. (2017). "Out im office?!" Sexuelle identität und geschlechtsidentität, (anti-)diskriminierung und diversity am arbeitsplatz. Edited by institut für diversity- und antidiskriminierungsforschung. Köln".

Gates, T. \& Viggiani, P. (2014). "Understanding lesbian, gay, and bisexual worker stigmatization: a review of the literature". International Journal of Sociology and Social Policy, 34(5/6), 359-374, doi: 10.1108/IJSSP-07-2013-0077.

Gedro, J.A. (2006). "Lesbians: Identifying, facing, and navigating the double bind of sexual orientation and gender in organizational settings". New Directions for Adult and Continuing Education, 2006(112), 41-50, doi: 10.1002/ace.235.

Gedro, J.A. (2019). "Lesbians in work settings: Identity, visibility, and strategy". Journal of Lesbian Studies, 23(2), 141-143, doi: 10.1080/10894160.2019.1520576.

Goffman, E. (2003). Stigma. Über techniken der bewältigung beschädigter identität, Frankfurt am Main: Suhrkamp.

Graml, R., Hagen, T., Ziegler, Y., Khachatryan, K., and Herman, R.A. (2020). "Lesbische frauen in der arbeitswelt". Working Paper No.15. FRA UAS, Business and Law.

Griffin, P. (1992). "From hiding out to coming out: empowering lesbian and gay educators". Journal of Homosexuality, 22(3-4), 167-196, doi: 10.1300/J082v22n03_07.

Heintz, P.A. (2012). "Work-Life dilemmas emerging from lesbian executives' narratives". The Career Development Quarterly, 60(2), 122-133, doi: 10.1002/j.2161-0045.2012.00010.x.

Hodson, J., Jackson, S., Cukier, W., and Holmes, M. (2018). "Between the corporation and the closet". Equality, Diversity and Inclusion: An International Journal, 37(3), 283-297, doi: 10.1108/EDI-042017-0093. 
OMJ 19,3

King, E.B., Mohr, J.J., Peddie, C.I., Jones, K.P., and Kendra, M. (2017). "Predictors of identity management”. Journal of Management, 43(2), 476-502, doi: 10.1177/0149206314539350.

Köllen, T. (2015). "The impact of demographic factors on the way lesbian and gay employees manage their sexual orientation at work". Management Research Review, 38(9), 992-1015, doi: 10.1108/ MRR-05-2014-0099.

Lehtonen, J. (2016). "Experiences of Non-Heterosexual and trans youth on career choice and in the workplace”. In T. Köllen, (Ed.): Sexual orientation and gender issues in organizations: Global perspectives on LGBT global diversity, pp. 289-306. Springer.

Losert, A. (2004). "Lesbische Frauen im Angestelltenverhältnis und ihr Umgang mit dieser Lebensform am Arbeitsplatz". Master's thesis in sociology at the Carl von Ossietzky University of Oldenburg.

Meinhold, F. \& Frohn, D. (2016). "Daily work out? The relationship between self-representation, degree of openness about one's gay or lesbian identity, and psychological stress in the workplace", in Köllen, T., (Ed.): Sexual orientation and gender issues in organizations: Global perspectives on LGBT global diversity, pp. 321-338. Springer.

Murphy, L.D., Thomas, C.L., Cobb, H.R., and Hartman, A.E. (2021). "A review of the LGBTQ+ workfamily interface: What do we know and where do we go from here?" Journal of Organizational Behavior, 42(2), 139-161. doi: 10.1002/job.2492.

Ng, E.S. \& Rumens, N. (2017). "Diversity and inclusion for LGBT workers: Current issues and new horizons for research". Canadian Journal of Administrative Sciences/Revue Canadienne Des Sciences de L'administration, 34(2), 109-120, doi: 10.1002/cjas.1443.

Oswald, A.J., Proto, E., and Sgroi, D. (2015). "Happiness and productivity”. Journal of Labor Economics, 33(4), 789-822. doi: 10.1086/681096.

Ozeren, E. \& Aslan, A. (2016). "Understanding the identity work of LGB workers using the practice theory lens". In T. Köllen, (Ed.), Sexual orientation and gender issues in organizations: Global perspectives on LGBT global diversity, pp. 467-480. Springer.

Ragins, B.R. (2004). "Sexual orientation in the workplace: the unique work and career experiences of gay, lesbian and bisexual workers". Research in Personnel and Human Resources Management, 23, 35-120, doi: 10.1016/S0742-7301(04)23002-X.

Randstad. (2020). "Randstad workmonitor 2020 report". Retrieved from https://workforceinsights. randstad.com/hubfs/Workmonitor/Randstad-Workmonitor-December2020.pdf (accessed 8 November 2021).

Roberson, Q.M. (2006). "Disentangling the meanings of diversity and inclusion in organizations". Group \& Organization Management, 31(2), 212-236, doi: 10.1177/1059601104273064.

Rodriguez, E. \& Etengoff, C. (2016). "Religious workplaces: the joys, trials and tribulations of LGBT clergy". In T. Köllen, (Ed.): Sexual orientation and gender issues in organizations: Global perspectives on LGBT global diversity, pp. 181-196. Springer.

Shore, L.M. (2011). "Inclusion and diversity in work groups: a review and model for future research". Journal of Management, 37(4), 1262-1289, doi: 10.1177/0149206310385943.

Steffens, M., Niedlich, C., and Ehrke, F. (2016). "Discrimination at work on the basis of sexual orientation: Subjective experience, experimental evidence, and interventions”. in Köllen, T., (Ed.), Sexual orientation and gender issues in organizations: Global perspectives on LGBT global diversity, pp. 367-388. Springer.

Thiessen, V. \& Blasius, J. (1998). "Using multiple correspondence analysis to distinguish between substantive and nonsubstantive responses". in Blasius, J. \& M. Greenacre, (Eds), Visualisiation of categorical data, pp. 239-252. San Diego: Academic Press.

Trau, R.N.C. (2015). "The impact of discriminatory climate perceptions on the composition of intraorganizational developmental networks, psychosocial support, and job and career attitudes of employees with an invisible stigma”. Human Resource Management, 54(2), 345-366, doi: 10.1002/hrm.21630. 
Velez, B.L. \& Moradi, B. (2012). "Workplace support, discrimination, and person-organization fit: Tests of the theory of work adjustment with LGB individuals”. Journal of Counseling Psychology, 59(3), 399-407, doi: 10.1037/a0028326.

Sexual identity management

Vries, L.D., Fischer, M., Kasprowski, D., Kroh, M., Kühne, S., Richter, D., and Zindel, Z. (2020). "LGBTQI*-menschen am arbeitsmarkt: hoch gebildet und oftmals diskriminiert". DIW Wochenbericht, 36, 619-627.

Webster, J., Adams, G., Maranto, C., Sawyer, K. \& Thoroughgood, C. (2017). "Workplace contextual supports for LGBT employees: A review, meta-analysis and agenda for further research". Human Resource Management, 57(1), 193-210, doi: 10.1002/hrm.21873.

\section{Corresponding author}

Kristine Khachatryan can be contacted at: kristine.w.khachatryan@googlemail.com

For instructions on how to order reprints of this article, please visit our website: www.emeraldgrouppublishing.com/licensing/reprints.htm Or contact us for further details: permissions@emeraldinsight.com 